\title{
HIPERCONTEXTOS, ARTE Y EDUCACIÓN.
}

HIPERCONTEXTOS, ARTE E EDUCAÇÃO.

HYPERCONTEXTS, ART AND EDUCATION.

\section{CARLOS ESCAÑo}

jcescano@uma.es

Universidad de Málaga

Tipo de artículo: original

AGRADECIMIENTOS: a Carolina González Gómez, por su amabilidad y su trabajo de traducción al portugués.

\section{RESUMO}

Hipercontextos, Arte e Educação. Um estudo prévio do conceito Hipercontexto dar-nos á o ponto de partida para uma futura análise, mais profunda,sobre as praticas estabelecidas e estratégias pedagógicas actuais na educação artística, em relação à(s) cultura(s) ibero-americana(s), na Internet. Esta análise ainda não se realizou.Esse estudo poderia ser muito relevante : porque por um lado, na América Latina, os países são na maioria de cultura iberoamericana, tendo em conta os pontos de vistas demográfico e idiomático-cultural. Por outro lado, Espanha e Portugal são as portas européias para a outra margem.

Este texto pretende ser assim esse estudo primogenito e estabelecer o debate apontando certas bases teóricas sobre o conceito de hipercontexto na sua relação com a arte e educação artística.

O Hipercontexto pode ser o veículo e lugar da actividade educativa artística comprometida, real e transformadora da sociedade através da Rede. A actividade hipercontextual na educação (artística) deve afastar-se do padrão mercantilista e fazer exercício de crítica e construção pedagógico-social.

\section{RESUMEN}

Hipercontextos, Arte y Educación. Un estudio previo del concepto Hipercontexto nos dará las claves para un análisis posterior, más profundo, de la actividad real de las estrategias pedagógicas actuales propias de la educación artística, vinculadas a la(s) cultura(s) ibero-americana(s), en Internet. Este análisis aún no se ha realizado. Un estudio que abarcaría ese arco cultural por motivos poderosos: por un lado, América Latina, países en su mayoría de cultura iberoamericana, supone desde los puntos de vistas demográfico e idiomático-cultural el peso específico mayor en el continente. Por otro lado, España y Portugal son las puertas europeas hacia la otra orilla. 
Este texto pretende ser ese estudio primigenio y establecer el debate apuntando ciertas bases teóricas del concepto hipercontexto en su relación con el arte y su educación.

Hipercontexto como vehículo y espacio de una actividad educativa artística comprometida, real y transformadora de la sociedad a través de la Red. La actividad hipercontextual en la educación (artística) debe de alejarse del patrón mercantilista y ejercer de crítica y construcción pedagógico-social.

\section{ABSTRACT}

Hypercontexts, Art and Education. A previous study of the concept Hypercontext will give us the keys to further and deeper analysis about actual activity of teaching strategies specific to current art education, linked to the Ibero-American (s) culture (s) online. This analysis has not been implemented yet. A study covering such cultural arch would be justified by two powerful reasons: firstly, because most countries in Latin America belong to Ibero-American culture, and Latin America, takinf into account demographic and idiomatic-cultural points of views, and its higher specific weight on the continent. On the other hand, Spain and Portugal are European doors to the other shore.

This text aims to prepare the first study and discusses the theoretical bases about the concept of "hypercontext" relating to art and education.

Hypercontext can be used as a vehicle and place for authentic artistic-educational commitment, which promtes changes in society. Through Internet. Hypercontextual activity in (art)education one should be away from the mercantilist pattern and should exercise critical and pedagogical-social construction.

PALABRAS-LLAVE: Internet. Hipertextualidad. Hipercontexto.Investigación. 
INTRODUCCIÓN. Un hipercontexto orientado al arte y a la educación

A principio de la década de los 90 emergió el World Wide Web y con éste la posibilidad, el medio y el instrumento de comunicación (y educación) multimedia más óptimos hasta la actualidad. Cerca de veinte años han permitido una relevante evolución en la técnica, en la significación y en la usabilidad: desde el HTML más básico hasta el concepto del web 2.0.

Inevitable y obligatoriamente la Educación Artística, como otras áreas de conocimiento propias de las Ciencias Sociales, ha sido susceptible a la implicación e interrelación con este medio. Estas ya numerosas relaciones mantuvieron en un principio una seña de identidad anglosajona, no obstante, desde hace algún tiempo podemos hablar de una participación importante de las culturas no anglófonas en general, y de cultura(s) ibero-americana(s) en particular.

Así, asumiendo esa perspectiva histórica de casi dos décadas como tiempo propicio para establecer ciertas conclusiones, podemos señalar que precisamente esa contrastable importancia en comentadas participaciones y acciones ponen de relevancia la obligatoriedad de realizar un estudio sobrio que organice y exponga las distintas actuaciones desde los orígenes, las tendencias y estilos desarrollados, propuestas y evoluciones técnicas dentro de la educación artística propia de los contextos de IberoAmérica. Este estudio aún no se ha realizado. Un estudio que abarcaría ese arco cultural por motivos poderosos: por un lado, América Latina, países en su mayoría de cultura iberoamericana, supone desde los puntos de vistas demográfico e idiomático-cultural el peso específico mayor en el continente. Por otro lado, España y Portugal son las puertas europeas hacia la otra orilla. Asimismo, las líneas teóricas construccionistas y critico-pedagógicas, alternancia actual a la visión crematística y mercantilizada de la educación, se erigen como señas de identidad de una educación que ha encontrado sus mejores aliados en los contextos señalados. Citado eje ibero-americano supone, bajo mi punto de vista una alternativa cultural (más enriquecedora) a la actual predominancia angloa- mericana y quizá, sólo por este motivo, necesitamos de ese análisis para conocer -y fortalecer- las conexiones pertinentes para con nuestra disciplina optimizando sus posibilidades.

\section{Hipercontexto: ¿explicación necesaria?}

Aunque parezca que la simple intuición nos ofrezca una explicación directa del término, deberíamos hacer una pausa ante el mismo para un análisis más penetrante.

Debemos para ello valorar, en primera instancia, otros conceptos afines que se muestran ineludibles para su discernimiento claro y conciso. Hipertextualidad es el primero de ellos.

En los entornos ibero-americanos, tanto para el mundo de habla lusa como hispana, el neologismo oficioso de hipertextualidad puede, en un principio, mantener una única acepción, la informática, cuando lo ubicamos en el marco de Internet. Esto es porque, aunque el vocablo en cuestión aún no está recogido oficialmente, en ambas instrucciones lingüísticas, sí lo está el término hipertexto. Por ejemplo, éste se explica en el adelanto de la vigésimo tercera edición del diccionario de la Lengua Española (2008) como aquel "conjunto estructurado de textos, gráficos, etc., unidos entre sí por enlaces y conexiones lógicas". Asimismo, en portugués parece mantener casi idéntica acepción. De esta manera, podríamos comprender la hipertextualidad como cualidad y condición del hipertexto. $\mathrm{Y}$ es bien cierto que este último concepto, hipertexto, en su ámbito natural de Internet, viene lógicamente del campo de la programación computacional: el Lenguaje de Etiquetas de Hipertexto, es decir el celebérrimo HTML (Hypertext Markup Language).

Pero la hipertextualidad ha sido estudiada bajo otra acepción, ya que ésta es una idea trabajada con anterioridad a la emergencia del World Wide Web, momento de visibilidad popular de la programación HTML y que aún hoy es el soporte programacional más extendido del mundo web. Fue Gérard Genette (1982) quien, siguiendo las teorías de M. Bakhtin y J. Kristeva, expuso la idea de transtextualidad literaria dando explicación a toda relación que 
pone a un texto en correspondencia con otros. Así, definía varias relaciones transtextuales, entre las que se encontraba justamente la hipertextualidad. Ésta se refiere a la relación existente entre un hipotexto (obra original) y un hipertexto, el cual partiendo del anterior lo amplía, modifica, transforma o elabora -v.g.: la Odisea de Homero como hipotexto y la Eneida de Virgilio como hipertexto (STAM, 1999). Como se ha indicado este concepto ha sido vinculado al mundo literario y a la crítica, mas otros discursos narrativos expresivos han sabido asumir sus posibilidades como es el caso cinematográfico, o incluso el pictórico.

Valorar en Internet la hipertextualidad, a través de este punto de vista, supone entonces abrir la puerta a otra acepción interesante de este término. Aquí es cuando realmente comienza a entrar en juego el concepto hipercontexto.

Pero antes vayamos directo al segundo término obligado en esta disección conceptual: contexto.

Contextus, raíz latina del vocablo, alude a la noción de contextura, y ésta se define como "disposición y unión respectiva de las partes que juntas componen un todo" (GARCÍA DE DIEGO, V. y otros, 1999: 110). Asimismo, podemos destacar la explicación lusa, y su homónima castellana (o definiciones, en todo acaso, muy similares) que explicita como contexto aquel "conjunto de circunstâncias que rodeiam um acontecimento; situação; conjuntura" o aquella "totalidade das circunstâncias e dos factores históricos, sociais, culturais, etc., que possibilitam, condicionam ou determinam a produção e a recepção de um texto" (INFOPÉDIA, 2008).

Si cruzamos la visión de contexto e hipertextualidad podríamos deducir que el hipercontexto amplía, modifica, elabora o transforma un hipocontexto, un contexto original, un conjunto de circunstancias que rodean un acontecimiento o una totalidad de circunstancias y factores socioculturales que determinan y posibilitan la propia producción de un texto. En este caso podríamos entender el hipocontexto como conjunto de circunstancias que rodean a los acontecimientos socioculturales propiciatorios para la emergencia de textos. Estos textos son nuestras narrativas diarias. Narrativas vivificadas por nuestras propias vidas que configuran un hipotexto en sí. La hipercontextualidad sería la realización de una transformación y ampliación de ese hipocontexto. La noción, por tanto de hipercontextualidad, hace referencia a la elaboración, en definitiva, de otro contexto que se torna diferente al que se refiere, pero con una esencia común.

Esta sería la base de un (no) lugar orientado a la educación en Internet. En otras palabras, cuando hablamos de hipercontextualidad en Internet no estamos señalando, en consecuencia, la simple existencia y uso de una efímera página web. Y cuando aludimos a la hipercontextualidad en Internet en relación con la educación, tomando en cuenta lo acabado de describir, hablamos de ese conjunto de circunstancias que rodean un acontecimiento, en este caso educativo, y que se amplían, transforman y modifican en la Red. Por lo tanto, no estamos hablando de meras páginas web que publicitan más o menos contenidos, estamos hablando de sitios web que continúan la labor educativa en toda su complejidad, que toman en serio las posibilidades que brinda el (hiper) contexto Internet. Que hace buena (y viva) la noción de Jordi Escalé: Internet es cuestión de ser, no de estar (2001). La Red debe ser tenida en cuenta como contexto y esto es mucho más rico que entender su existencia como una concatenación de simples "anuncios publicitarios" de empresas que ofrecen sus servicios, como usualmente tantos sites están presentes en el World Wide Web.

Los contextos ubicados en Internet, al igual que los no virtuales y dotados de fisicidad (los "reales"), trascienden desde lo cuantitativo a lo cualitativo, del plano puramente geoespacial hacia un plano cultural y, en nuestro caso, dotados de potencia educativa. Esos hipercontextos asumen como suyas todas las posibilidades de la hipertextualidad y de lo hipermedia, de la misma manera que un contexto asume todas las posibilidades de la textualidad y de sus medios.

La educación así lo exige. De esta manera, cualquier entorno web -teniendo en cuenta la evolución tecnológicaorientado a la educación debiera asumir y potenciar las posibilidades que esta brinda en todas sus dimensiones: 
accesibilidad e interactividad plural más ese carácter multimedia e interdisciplinar, cualidades propias del medio. Esta tarea se le es encomendada al profesional de la enseñanza, pero siempre dotándola de un fin, sin éste no podemos hablar de realización plena de estrategias hipercontextuales y su uso óptimo.

La educación artística es un vehículo y disciplina idóneos para ser ejemplo y vanguardia de esa encarnación de facultades educativas en Internet (ESCAÑO, 2005), aúna los intereses estéticos de un medio por naturaleza expresivo, hipermedia y audiovisual y, por otro lado, los intereses directamente educativos de un medio de comunicación tan extendido y de tantas potencialidades.

\section{Necesidades hipercontextuales}

"La dicotomía entre teoría y práctica, la universalidad de un conocimiento exento de condicionamiento histórico-sociológico, el papel de la filosofía como explicación del mundo e instrumento para su aceptación, la educación como pura exposición de hechos, como transferencia de valores abstractos, de la herencia de un saber casto, todo eso son creencias de la conciencia ingenua del "analfabeto" político siempre proclama". (FREIRE, 2001: 75).

En un principio, el presente apartado lo ubicaremos en el entorno universitario, puesto que es sinónimo, a priori, de investigación y vanguardia educativa.

En la compilación "Investigación en Educación Artística”, coordinada por Ricardo Marín y editado en el año 2005 por la Universidad de Granada y la Universidad de Sevilla, pude recoger, en el capítulo "Posibilidades y realidades de Internet en la Educación Artística" la visión del profesor Santiago Campión sobre la influencia que la aparición y desarrollo de Internet ha supuesto en contenidos y métodos educativos orientados a la universidad. Ahora, por su pertinencia, las cito textualmente:

"El ámbito de la educación, y en particular el de la formación superior, no puede permanecer indiferente a este impacto; esta apreciación se ve respaldada por la necesidad de generar y desarrollar unos contenidos adecuados al medio (las redes, la interac- tividad, la supresión de las barreras espacio-temporales, los sistemas multimodales...), pero también al fin: la formación, la educación y la mejora cualitativa y cuantitativa de los procesos de enseñanza-aprendizaje (CAMPIÓN, 2008 [2001]).

Santiago Campión pronunció estas palabras en el inicio de su intervención para el II Congreso Internacional de la Lengua Española, celebrado en el 2001. Subrayo la importancia de la cita de ambas fechas: 2001, momento en el que el profesor alertaba de la importancia de la vinculación de la educación a Internet, y 2005, utilizando tales palabras para vincularlas a la praxis educativa artística. Ambas son fechas enmarcadas en la presente década pero que la celeridad del ciberuniverso las impregna de un halo de caducidad, con fuerte carga obsolescente. Aún así, en el presente texto cobran un sentido muy actual, puesto que su contenido tiene tal vigencia que, incluso con el paso de lustro y medio, aún no se ha desarrollado: no se ha materializado su advertencia y/o mandato en la generalidad educativa universitaria. Nos referimos a la necesidad de generar y desarrollar contenidos para con los medios, y, sobre todo, para con el fin educativo.

La profesora Dolores Álvarez en su texto sobre investigación del aprendizaje educativo orientado al cosmos web deja patente que "las posibilidades de uso de Internet para la Educación Artística, incluso en el ámbito formal, son también múltiples: desde la obtención de material como textos críticos o colecciones de imágenes, hasta la creación y tratamiento de imágenes, organización de material en hipertexto, posibilidades interpretativas y de significados en lecturas visuales individuales o grupales, conexión con otras realidades culturales, creación de imágenes animadas, creación individual, creación colectiva, desarrollo de nuevas formas basadas en el ciberespacio. El aprendizaje en conexión permite compartir proyectos creativos, comunicaciones mediante correo electrónico, grupos de discusión, foros, 'chat', compartir material escrito, visual o multimedia, etc" (ÁLVAREZ, 2005: 340). Estas palabras están corroboradas por la práctica y, realmente, si hablamos de contenidos de la educación artística adecuados a los medios, sí existen diversos ámbitos web adecuados -aparentemente- al medio. Existen ejem- 
plos que así lo corroboran y funcionan desde hace algunos años (ver ejemplos: ESCAÑO, 2005). Sin embargo, la asignatura pendiente aún radica en la falta de consecución de contenidos adecuados a la finalidad. Efectivamente estamos ante un flujo continuo de contenidos en la Red que conforman un conjunto que podríamos calificar de procesual, no son productos acabados. Este conjunto es dinámico e implica interacciones, palabras, gráficos e imágenes que se erigen como iconos que conllevan significados en forma de acciones (ÁLVAREZ, 2005: 332). Subraya Álvarez Rodríguez que la construcción del discurso se hace al instante y se crea continuamente en la navegación. Estas afirmaciones califican el desarrollo del conocimiento en la web y para ello necesitamos esos medios definidos por la profesora, pero, por supuesto, también -insisto en las palabras de Campión-, fines: la formación, la educación y la mejora cualitativa y cuantitativa de los procesos de enseñanza-aprendizaje. En otras palabras, la generación de verdaderos hipercontextos atendiendo a la definición aportada en estas letras: espacios de educación ajustados realmente a un nuevo tiempo y lugar.

Así, la labor educativa que ha asumido realmente esa adecuación de medios y fines es menor que la que aparentemente se anuncia o se percibe a primera vista en Internet. Indudablemente, la universidad -en relación con la educación artística-, como colectivo, no es la más representativa en este sentido: esa labor sigue siendo más individual o grupuscular antes que ser realizada en grandes grupos colectivos (centrándonos en el caso de habla hispana). De cualquier modo, se hace necesario establecer una investigación que determine las circunstancias reales y prácticas de los hipercontextos existentes.

En mayo de 2008, en el Congreso Iberoamericano de Educación Artística de Beja, Portugal, se lanzó una propuesta de investigación interuniversitaria orientada al análisis de hipercontextos. De esa propuesta corresponden partes precedentes del presente texto. La idea planteaba realizar un estudio sobre la participación $h i$ percontextual de las múltiples culturas existentes en las dos orillas ibero-americanas en relación con la Educación Artística (analizar génesis, objetivos, metodologías y consecuencias). Un análisis que dilucide el estado real de la actividad educativa-artística de los hipercontextos ibero-americanos. En este sentido, se adelantaron indicios o referencias web sobre posibles hipercontextos existentes. Sin embargo, no cabe duda que previo a la posible realización y puesta en marcha de esta propuesta investigadora, formulada con carácter informador -de ahí su naturaleza expositiva como comunicación-, se hace necesario un estudio tanto del término y concepto (ya apuntado en estas líneas) como de las características esenciales que harán factibles o definibles a los hipercontextos en educación artística. Se hace obligatorio aportar las bases teóricas que soporten los retos socioeducativos del (hiper) contexto iberoamericano educativo-artístico: expandir la educación, trascender del texto al contexto y, posteriormente, al hipercontexto ${ }^{1}$.

\section{Características hipercontextuales para con la educa- ción artística:}

Las características que desarrollaremos se vinculan hipertextualmente entre ellas. Así, como de una muñeca Matrioska -nombre de las famosas muñecas rusas- se tratara, iremos observando cómo se asumen unas a otras partiendo de la primera.

\section{A. Trascendencia educativa.}

"Empezaré afirmando o reafirmando que, si no superamos la práctica de la educación como pura transferencia de conocimiento que sólo describe la realidad, bloquearemos la emergencia de la conciencia crítica, reforzando así el "analfabetismo" político. Tenemos que superar este tipo de educación -si nuestra opción es realmente revolucionaria- y reemplazarla por otra, en que conocer y transformar la realidad sean exigencias recíprocas" (FREIRE, 2001: 76).

1 A partir de este momento, para distinguir en las presentes letras aquella educación propiciada en las aulas o fuera de ellas, pero en la realidad física, de la ejercida en los medios virtuales, en la Red (pero que en definitiva también forma parte de la realidad), hablaremos de educación en contextos (para la primera) y educación en hipercontextos (para la segunda). De esta manera, se evitará la confusa distinción de educación en un "marco real" y en un "marco virtual", puesto que, en el segundo caso, parece aludir que esa virtualidad se le puede suponer a la educación, impregnándola así de un matiz peyorativo o simplemente falsario. 
Hacemos nuestras estas palabras de Paulo Freire como declaración de principios en una sociedad en crisis y en desigualdad, además de calificar y hacer visible el modelo (necesario) al que aludimos como opción pedagógica y educativa, que no es otro que la(s) corriente(s) de la pedagogía crítica. Puesto que concebimos la pedagogía crítica como una forma de política cultural y ello significa subrayar la importancia que tienen comprender la enseñanza y la pedagogía como una expresión de la teoría social radical (McLAREN, 1997).

En este sentido, la educación en los hipercontextos, sea de la naturaleza o disciplina que sea, tanto artística como matemática o histórica, debe beber de la misma intención y base pedagógica. Debe trascender de esa educación propia del contexto hacia el entorno del hipercontexto. La educación en los hipercontextos debe ser educación ante todo. En este sentido, la educación artística debe asumir tal compromiso en contextos e hipercontextos.

Aquellos websites educativos que acumulan posibilidades de acceso a la información (recursos como banco de imagen, listados de webs, etc.) pero no aportan intenciones para la transformación social, olvidan una faceta esencial de la educación, abandonando así una finalidad sustancial de la misma. En esta línea, no participarían de un verdadero hipercontexto.

Iguales en las Tres mil (http://igualdad3000.blogspot. com/) es un modélico ejemplo de hipercontexto trascendido (y trascendente). Un blog creado y recreado por alumnado y profesorado, agentes implicados en contar la misma historia: la de la educación, pero con distintas historias, las particulares voces, creando un itinerario virtual con una dinámica real, un mapa y cuaderno de bitácora de la colectividad educativa. Un proyecto puesto en marcha desde septiembre del 2006 con el objetivo claro de la igualdad dentro de en un entorno muy nece- sitado de esa realidad, pero no más que cualquiera de los nuestros. El proyecto, un espacio para la igualdad, está desarrollado por los departamentos de Filosofía y Educación Plástica del Instituto de Enseñanza Secundaria Antonio Domínguez Ortiz de Sevilla (España), ubicado en uno de los barrios más marginales de la ciudad, dentro del polígono sur, y cuyo nivel de absentismo suponía un gravísimo problema escolar. Proyectos como Iguales en las Tres Mil, junto con otras actividades hipercontextuales y contextuales, han reducido drásticamente el índice de absentismo y han provocado que sea una referencia

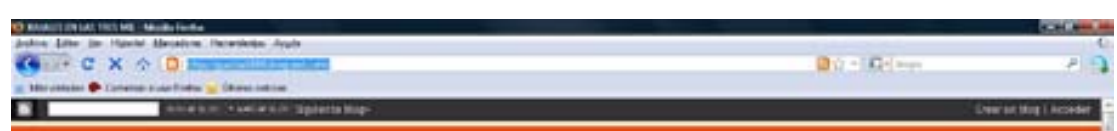

IGUALES EN LAS TRES MIL

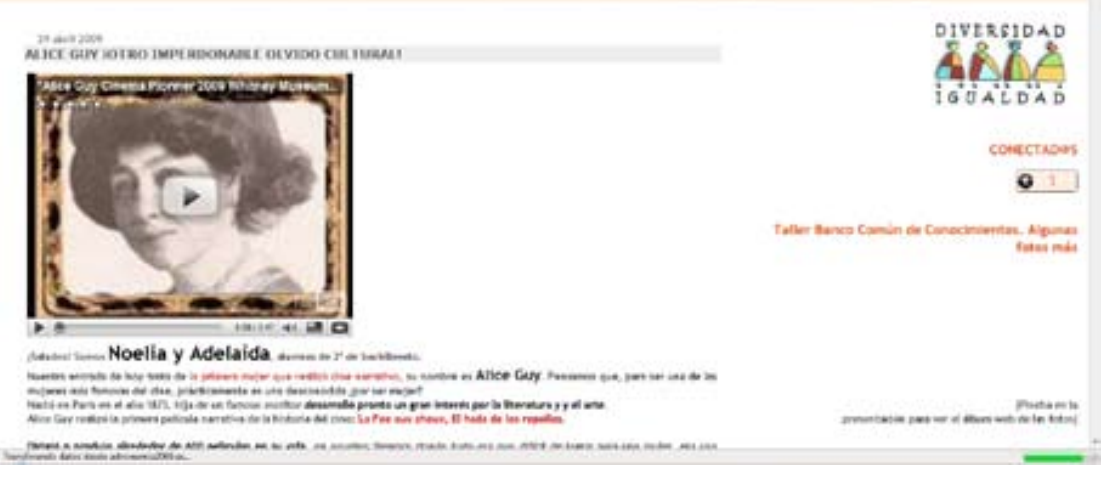

Iguales en las Tres mil. http://igualdad3000.blogspot.com/

pedagógica en foros educativos. El trabajo interdepartamental, la vinculación educativa entre disciplinas como la educación plástica y la filosofía, la mediación tecnológica y, sobre todo, la implicación y motivación del alumnado, han hecho que esta labor docente y discente una realidad exitosa: todos iguales en las Tres mil verdaderamente.

\section{B. Medra sociocultural.}

"Los futuros profesores y profesoras se encuentran en una encrucijada ideológica en cuanto a las responsabilidades cívicas y políticas que asumen al considerarse no sólo profesorado crítico comprometido, sino teórico cultural" (GIROUX, 1999: 53).

Es inevitable señalar la medra sociocultural como consecuencia de la trascendencia educativa tanto en los con- 
textos como en los hipercontextos. Esta es la segunda muñeca, la primera que sacamos del interior de original matrioska.

En definitiva, la finalidad de la educación, ya señalada, no es la mera transferencia de conocimiento descriptivo. No estamos ante una elemental transmisión de conocimientos verticales y estáticos, como recoge Villar aludiendo a Ramírez y Ortiz, sino ante la creación de una situación pedagógica en la que los seres humanos se descubren a sí mismos, se reinventan y aprenden a tomar conciencia del mundo en el que viven e interactúan (VILLAR, 2009). Asimismo la educación debe suponer y acometer una medra y necesaria transformación de ese mundo del que se toma conciencia, en la medida que la injusticia, la desigualdad y la falta de libertad lo subyuguen.

Los hipercontextos relacionados con la educación artística deben asumir esa misma pretensión.

\section{Epistemología p2p: tráfico de conocimiento, demo- cracia epistemológica. Compartiendo pedagogías.}

Vieja letanía docente: "los alumnos no quieren hacer nada y no quieren aprender nada". Pues sí, sí quieren, y muchas cosas. Distinto es que no quieran aprender y hacer lo que le decimos nosotros, cómo se lo deci-

mos

nosotros y cuando se lo decimos nosotros.

Juan José Muñoz. Profesor de I.E.S. y Coautor de Iguales en las Tres Mil

Es sin duda una de las características que se enfundan mejor en la metáfora de Internet, así como en su realidad, es decir, la democracia epistemológica es ejemplo vivo en Internet del tráfico de conocimiento, del compartimiento de pedagogías y de la enseñanza individualizada, persona a persona.

La expresión democracia epistemológica encierra una visión crítica. Una superación de aquella transmisión de conocimientos verticales y estáticos. Como deja explícito Paulo Freire: "Hay un punto de fundamental importancia que es preciso subrayar en la superación de la práctica educativa domesticadora y su remplazo por la liberado- ra. Me refiero a la imposibilidad de una praxis verdaderamente liberadora si el educador sigue el modelo del "domesticador". Mientras que éste es siempre el educador de los educandos, el educador para la liberación tiene que "morir" como educador exclusivo de los educandos a fin de renacer, en el proceso, como educador-educando de los educandos". (FREIRE, 2001: 77)

En la Red, por su condición, se hace real esa democracia y transacción epistemológicas. El fenómeno de los programas p2p (Peer to Peer), persona a persona, así lo pone de manifiesto claramente. Los distintos programas $\mathrm{p} 2 \mathrm{p}$ (eMule, Skype, BitTorrent, etc.), algunos odiados y perseguidos por los gobiernos como si fueran auténticos demonios (tanto los softwares como los gobiernos) suponen un paradigma perfecto para la acción pedagógica a nivel contextual como la esencialmente hipercontextual.

La Red exige que se explote esta cualidad no exclusiva de la misma pero sí muy reveladora y extendida en Internet, exige a la educación artística que se implique en la democratización real de la educación y en una polifonía bakhtiniana de discursos donde la jerarquía vertical epistemológica se difumine por su falta de conexión con la realidad y la vida, lugares donde el aprendizaje es multilateral y tantas veces asistemático. Así, el papel docente se desarrolla como autoridad funcional, promoviendo las libertades, la creación, la investigación crítica siendo el profesor un investigador crítico, proponiendo reflexiones, preguntas y repreguntas con los cuales el alumnado y el propio profesor construyen el conocimiento. El trabajo en red nos permite pensar en un cambio radical desde ambos puntos de vista: profesorado y alumnado (VILLAR, 2009).

Banco Común de Conocimientos (http://www.bancocomun.org) es un modelo de tráfico de pedagogías, de tráfico de conocimiento. Un proyecto que pretende asumir la democratización real de la educación, apostando por un modelo rizomático (plural, extensible, en crecimiento, transversal) en lugar del arborescente (jerárquico, unilateral, cerrado). El colectivo Platoniq puso en marcha su proyecto argumentando que: 
"El Banco Común de Conocimientos (BCC) es una experiencia piloto sobre el intercambio de conocimientos, una iniciativa para el aprovechamiento y la indexación colectiva del conocimiento significativo, potenciado a raíz de la expansión de la nuevas tecnologías y las redes digitales. BCC es un campo de acción colectiva basado en la transferencia de conocimientos y la educación mutua. Un laboratorio donde experimentar con nuevas formas de producción, aprendizaje y participación ciudadana” (BCC, 2006)

Un experiencia en la que todos, educandos y educadores, asumen el papel de todos, educadores y educandos, compartiendo pedagogías, aplicando la filosofía copyleft y finalmente mediado a través de la Red para su visibilización. Procurando así la medra sociocultural y la trascendencia educativa. (Tercera muñeca).

pero que trata de emular -igual que la perspectiva o el espacio cubista- a la experiencia sensorial, proponiendo una imagen especular, "al otro lado". Este concepto espacial obliga, al contrario que el punto de vista único, a descentralizar y salir de la propia perspectiva. El medio propicia que la creación se realice en la subjetividad de quien interactúa, en el desplazamiento por el hipertexto: hipermedia e interdisciplinar (ÁLVAREZ, 2003). Las palabras de la profesora son simbólicas y certeras. Simbólicas por la alusión al obligatorio cambio de perspectiva ante una realidad distinta (y sobre todo en la educación). Y certeras porque ese espacio y tiempo requieren, efectivamente, de una actividad subjetiva para su desarrollo y construcción. Una realización en la que la imagen-espacio e imagen-tiempo se desarrollan en común con el sujeto que la explora, y a su vez -pero "distinta"- con los múltiples individuos que acceden a esas coordenadas espaciotiempo. Esa obligación de la red nos

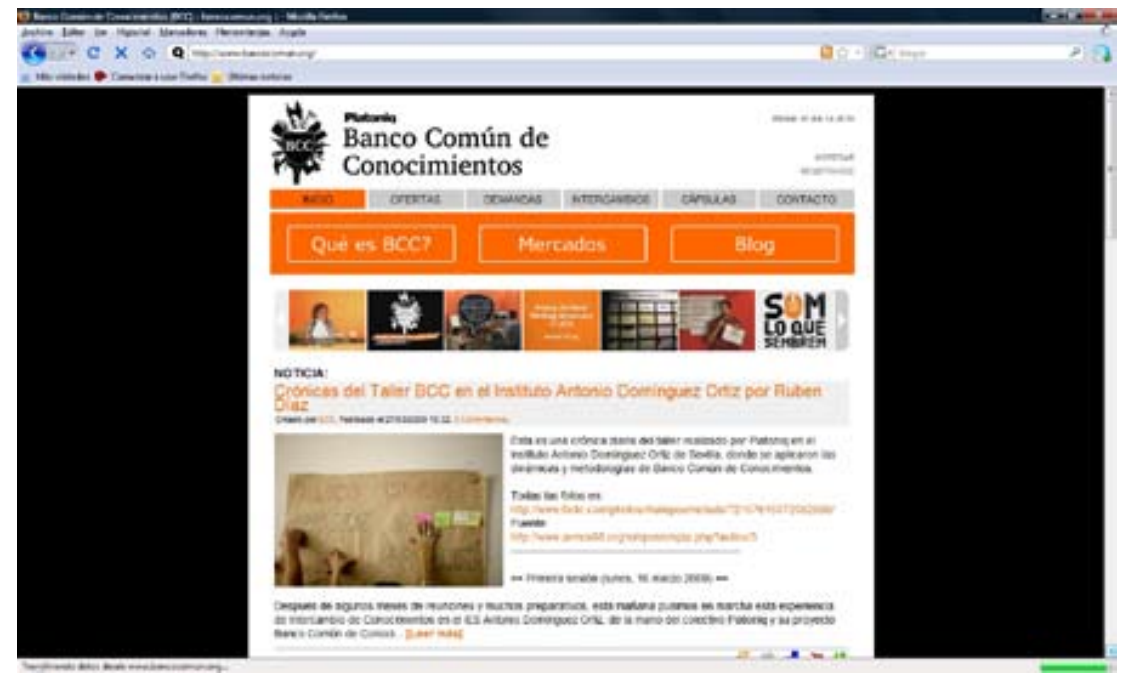

Banco Común de Conocimientos. http://www.bancocomun.org

\section{Mediación de la representación icónica.}

Finalmente, aludiremos a la mediación de la representación icónica como última característica referenciada.

Como explica Álvarez Rodríguez en el ciberespacio el espacio y el tiempo, como concepciones convencionales, se diluyen y la acción (interacción) crea nuevos significados instantáneos. La creación entraña acción en tiempo y espacio real. El ciberespacio es un espacio que no existe hace reflexionar que los contenidos ubicados en ese espacio también son construidos, no están ya ahí: estáticos y ajenos al usuario. Debieran ser construidos por cada uno de los participantes en el proceso del conocimiento.

Una vez más emerge la hipervinculación como fórmula educativa. Una vez más subrayamos la necesidad de las propuestas P2P educativas. Una vez más la mejora sociocultural tras la propuesta. Una vez más la trascendencia educativa. Una vez más una muñeca rusa.

En la construcción de ese espacio y tiempo para la ciberrealidad, y sus discursos interconectados, dotamos de un carácter fundamental a la mediación icónica; es decir, es sustancial la creación de imágenes y sonidos, signos gráficos y sonoros. El carácter multimedia y audiovisual es una obviedad en el discurso de Internet.

Si asumimos que en la construcción de Internet el papel de la representación iconográfica es esencial, estaremos 
señalando que el conocimiento para saber representar iconográficamente es fundamental. La educación artística tiene otra responsabilidad más de las que ya había asumido tradicionalmente.

No obstante, esa construcción del discurso espaciotemporal debe realizarse conforme a su condición: multimodal, interdisciplinar e intersubjetivo. De ahí que un hipercontexto deba asumir la elaboración educativa-democrática y participativa desde sus contenidos y formas.

Camon (http://www.tucamon.es/) se erige como modelo para otros hipercontextos educativo-artísticos. Un modelo de aprendizaje basado en el BeLearning, aprendizaje basado en la acción y en el descubrimiento autodidáctico. Una red social que se divide su acción creativa en cinco ámbitos: arte multimedia, música, cine, fotografía solidaridad/medioambiente. Un intercambio y exhibición de experiencias multimedias y audiovisuales.

ciertas bases teóricas del concepto hipercontexto en su relación con el arte y su educación.

Así, el análisis del término -y su relación cognitiva y pedagógica con las artes- nos ha permitido asumirlo como vehículo y espacio real (no "virtual") de la educación artística comprometida y transformadora de la realidad a partir de la plataforma Internet. Hecho que nos induce a repensar el concepto de Educación Artística a través de la Red alejándonos, por un lado, del patrón mercantilista (oferta de servicios contractuales) y, por otro, de la mera suma de posibilidades y recursos.

A partir de la teoría desarrollada y su pertinente casuística se muestra como la educación artística vía Internet transciende de esa suma de posibilidades, convirtiéndose en una suma de realidades, de hechos, de acciones. Es decir, establecer un auténtico hecho educosocial. Transformar el (con)texto existente de la enseñanza y aprendizaje de las artes. El discurso que sigue asumiendo la Red como una promesa de futuro, de múltiples probabilidades de recursos, dando así explicación al sentido de la educación en Internet, está anclado en una pre-ciber-historia que forma parte de una visión obsoleta y falaz de la realidad educativa y potencial de la propia Red.

IGUALES EN LAS TRES MIL ( http:// igualdad3000.blogspot.com/), BANCO COMÚN DE CONOCIMIENTOS (http://www.bancocomun.org), o CAMON ( http://www.tucamon.es) son casos claro de compromiso y (r)

\section{CONCLUSIONES}

En la introducción de este texto se exponía la intención objetiva de plantear un estudio previo del concepto $\mathrm{Hi}$ percontexto, el cuál nos aportaría las claves para un análisis posterior de la actividad real de las estrategias pedagógicas actuales propias de la educación artística, vinculadas a la(s) cultura(s) ibero-americana(s), en Internet. Un estudio que pretende establecer el debate apuntando evolución de la (ciber)educación, ejemplos hipercontextuales de trascendencia educativa, medra sociocultural, democracia epistemológica y mediadoras de la representación icónica. 


\section{REFERÊNCIAS BIBLIOGRÁFICAS}

ÁLVAREZ, M.D., (2003), 'De la copia de láminas al ciberespacio', Didáctica de la Educación Artística, 183-227.

ÁLVAREZ, M.D., (2005), 'Educación artítistica 'on-line': la investigación del aprendizaje artístico basado en la web', Investigación en Educación Artística, 325-352.

ARONOWITZ y otros (1998), 'Tecnociencia y cibercultura'. Barcelona: Paidós.

BANCO COMÚN DE CONOCIMIENTOS (2006) http://www.bancocomun.org, Visitada el 30 abril 2009.

CAMON ( http://www.tucamon.es, Visitada el 30 abril 2009.

ESCALÉ, J (2001): http://www.infonomia.com/tematiques/index. asp?idm=1\&idrev=7\&num=1 Visitada el 29 abril 2003.

ESCAÑO, C. y SAURA, y (2007), 'Educación Artística con TIC en el ámbito universitario', Actas del XII Congreso Internacional de Informática Educativa. Tecnologías para la educación y el conocimiento, UNED: Madrid.

ESCAÑO, C. (2005), 'Posibilidad y realidades de Internet en la Educación Artística. Propuesta para la Posmodernidad: un entorno virtual común y universitario orientado a la educación artística y su investigación', Investigación en Educación Artística, 373-394.

GENETTE (1982), 'Palimpsestes: La littérature au Second Degré'. París: Seuil.

GARCÍA DE DIEGO, V. y otros (1999): 'Diccionario ilustrado latino-español español-latino'. Barcelona: Bibliograf.

GIROUX, H. (1999), 'Pedagogía crítica como proyecto de profecía ejemplar: cultura y política en el nuevo milenio', La educación en el siglo XXI. Los retos del futuro inmediato, 53-62.

FREIRE, P. (2001) 'La importancia de leer y el proceso de liberación'. Madrid: Siglo XXI editores.

IGUALES EN LAS TRES MIL (2006), http://igualdad3000.blogspot. com/ Visitada el 30 abril 2009.

INFOPÉDIA (2008) ‘Dicionário de Língua Portuguesa' http://www.infopedia.pt/pesquisa?qsFiltro=14. Visitada el 10 Abril 2008.

McLAREN, P. (1997) 'Pedagogía crítica y cultura depredadora'. Barcelona: Paidós.

REAL ACADEMIA ESPAÑOLA (2008), 'Diccionario de la lengua española. Vigésima segunda edición’ http://www.rae.es. Visitada el 10 Abril 2008.

STAM, R. y otros (1999), 'Nuevos conceptos de la teoría del cine'. Barcelona: Paidós.

VILLAR, G. (2009), ¿Vieja Pedagogía con Nuevas Tecnologías? en la Educación Virtual' http://ciberwiki07.tumblr.com/post/4932775/ vieja-pedagog-a-con-nuevas-tecnolog-as-en-la . Visitada el 30 de abril de 2009 